\title{
Preparation, Characterization and Optimization of Repurposed Valproic Acid Loaded Carboxymethyl Chitosan Nanoparticles by Box-Behnken Design for Alzheimer Management
}

\author{
Ayush Jaiswal', Senthil Venkatachalam ${ }^{1, *}$, Anindita De ${ }^{2}$, Bhavesh Namdev${ }^{1}$, Ravikumar Ramaswamy ${ }^{3}$, \\ Jawahar Natarajan' \\ ${ }^{1}$ Department of Pharmaceutics, JSS College of Pharmacy, JSS Academy of Higher Education \& Research, Ooty, Nilgiris, Tamil Nadu, \\ INDIA. \\ ${ }^{2}$ Assistant Professor, College of Pharmacy, JSS Academy of Technical Education, Noida, INDIA. \\ ${ }^{3}$ Department of Advanced Materials and Engineering, Hanseo University, 360, Daegok-ri, Seosan-si 356 706, Chungcheongnam-do, \\ SOUTH KOREA.
}

\begin{abstract}
Aim/Background: Alzheimer's disease (AD) is one of the most ominous diseases, leads dementia but highest unmet till today. The new strategy needed via repositioning due to the limitation of existing therapies. Valproic acid is one of the first line drugs for epilepsy and bipolar disorder showed neuroprotective potential by decreased $A \beta$ production in AD. Methods: The objective of this research was to prepare the repurposed VPA loaded polymeric nanoparticles using carboxymethyl chitosan for management of AD through the intranasal route. Polymeric nanoparticle (PNPs) was prepared by ionic gelation method and optimization was done using Box-Behnken design (BBD) model. Results: Characterization of optimized PNPs was done for Particle size which was found to be $384 \pm 1.45 \mathrm{~nm}$ with drug release of $82.39 \% \pm 3.1$ after $48 \mathrm{hr}$. In vitro cytotoxicity using cell line, SH-SY5Y and IC ${ }_{50}$ value of optimized formulation was found to be $42.96 \mu \mathrm{g} / \mathrm{ml}$. EX vivo histopathological study was performed using goat nasal mucosa for the Nasalcilio toxicity studies which showed no inflammation and toxicity for VPA-CMC PNPs and indicate the safe formulation. Conclusion: The outcome of the research is a positive direction to reuse the VPA for the management of AD in the near future through the intranasal route.
\end{abstract}

Key words: Repositioning, Valproic acid, Design of Experiment, In vitro cell line study, Ex vivo study.

\section{INTRODUCTION}

Neurodegenerative diseases are the condition where neurons damaged and cannot be replaced by the body causes Alzheimer disease (AD), Huntington disease and Parkinson disease and many more neurological disorders are one of the burdens specifically for the elderly patients. Among them AD gab the attention due to its lack of treatment facility and only the available symptomatic strategies for management. AD starts slowly and with time and worsens with age. According to the 2015 survey, it affected 37.50 million people worldwide. AD caused due to
Amyloid beta plaques and intracellular neurofibrillary tangles, originated of proteolysis of Amyloid precursor protein and hyper phosphorylation of the microtubuleassociated tau protein respectively. ${ }^{1}$ There are many existing therapies which are used for the Alzheimer treatment among them Acetylcholinesterase inhibitors and Memantine are the leading ones. But AD management is only symptomatic and the existing therapies having the limitations of the dose-related side effects like diarrhoea, abdominal cramp, vomiting and nausea. ${ }^{2}$
Submission Date: 16-04-2020; Revision Date: 14-07-2020; Accepted Date: 20-01-2021

DOI: 10.5530/ijper.55.1s.39 Correspondence: Dr. Senthil Venkatachalam Department of

Pharmaceutics, JSS College of Pharmacy, JSS Academy of Higher Education \& Research, Ooty, Nilgiris, Tamil Nadu, INDIA. Phone no: +91 9842650602 Email id: senthil.v@jssuni. edu.in

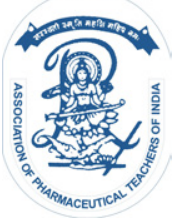

www.ijper.org 
Use of Cholinesterase inhibitors is also associated with pacemaker insertion, bradycardia and increased rates of syncope. The management of the disease is costly one specifically for the low-income countries. The crossing of the drug through the blood-brain barrier is one of the biggest challenge and the limitation for the existing therapy in the present scenario. The maximum reported adverse events in mean time trials were confusion, dizziness and headache.

Drug repurposing is one of the advantages of existing therapies. Drug repurposing is one of the latest trends and most economical alternative approach in drug advancement, with a history of successful reuse of currently available drugs. ${ }^{3}$ The biggest common model is the drug sildenafil (Viagra), authentically created by Pfizer for the intervention of hypertension and angina which was the reuse as a successful medication for erectile dysfunction. ${ }^{4}$ Many drug categories are there which can be repurposed for the AD such as AntiCancer (Carmustine, Paclitaxel and Bexarotene), AntiEpileptic (Valproic acid), Anti-Hypertensive (Carvedilol and Nilvadipine) and many drugs there which having is same mechanism and pathway likewise existing therapies for the treatment strategies shown in Figure 1.

Valproic acid (VPA) is an Anti-Epileptic drug and firstline choice for the treatment of epilepsy. VPA activates

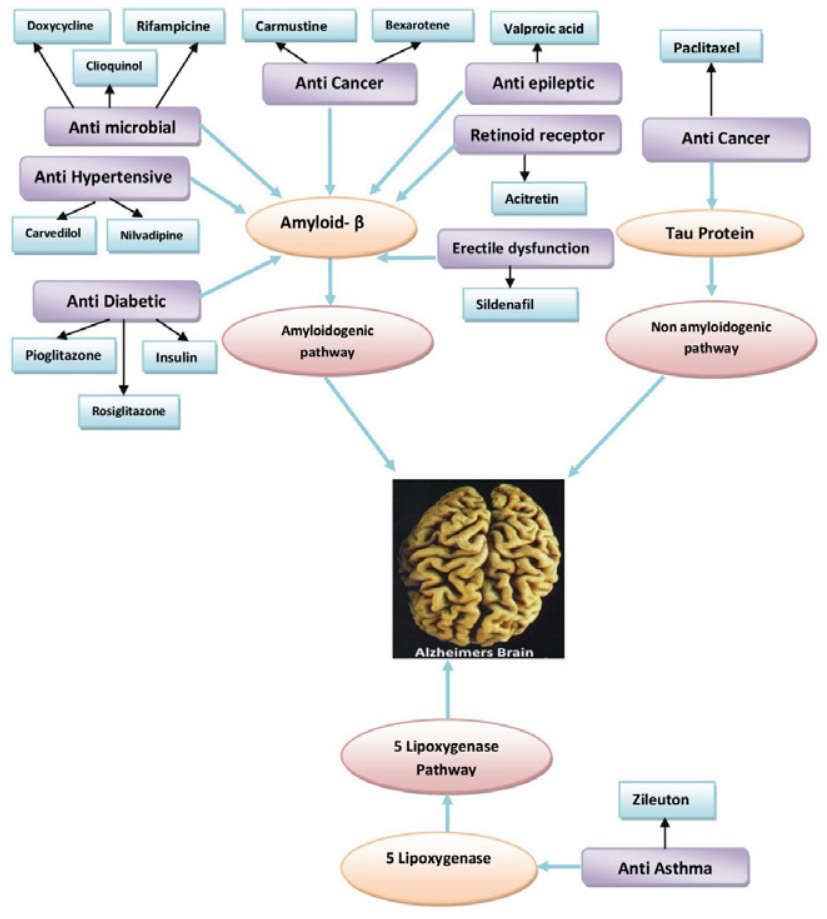

Figure 1: Repositioning of the different category of the drug along with pathways for the management of Alzheimer's disease. Most of the repositioning drugs fallow the Amloyid $\beta$ pathway. Even the Tau protein pathway and 5-lipoxygenases also play a prominent role in the treatment. extracellular signal-regulated kinase, a protein kinase which regulates AP-1 activities and negotiates neurotropic responses. The researcher also shows that VPA has an effect on gene expression and neuro-development. Scientist already showed that VPA inhibits glycogen synthase kinase (GSK)- $3 \beta$ mediated $\gamma$-secretase cleavage of the Amyloid precursor protein (APP) both in vitro and in vivo and rationale for the reuse of the drug for the treatment of $\mathrm{AD}$ for this research. ${ }^{2,5}$ The limitation of the VPA its poor solubility and lack of the crossing of BBB make research to focus on a specific delivery strategy.

From many decades the polymeric nanoparticle attracted researchers for targeting drug delivery in the brain due to their non-toxicity and mucoadhesive property. ${ }^{6}$ They are made of natural or synthetic polymers in which drug can be loaded, entrapped, encapsulated or attracted to nanoparticle for brain targeting for the affinity-based, adhesion based or simply by size based. In recent years, biodegradable polymers are in use like chitosan and its derivatives, gelatin and sodium alginate etc. showed great potential for delivering the drugs specifically to the brain. The great advantage of the polymeric nanoparticle is that they broke down into a biologically acceptable molecule that is metabolized and eliminated by the body through the metabolic pathways. Polymeric nanoparticle increases the stability of any pharmaceutical agent and delivers a high concentration of drug to a specific site through the specific route to overcome the problem of BBB crossing.

Route of administration by oral is always acceptable but the limitation associated with it is a blood-brain barrier (BBB) which hinder the drug transportation inside the brain. Recently nose to brain drug delivery is one of the easiest and well-accepted methods as a route of administration specifically for brain targeting. ${ }^{7}$ It avoids the blood circulatory clearance and it is noninvasive method comparable to other routes. The main routes through the intranasal delivery are olfactory epithelium and trigeminal nerve pathways. This route is the bypass of $\mathrm{BBB}$. Based on the rational the research work specifically focused to optimize and develop VPA loaded polymeric nanoparticle for the management of AD through intranasal route.

\section{MATERIALS AND METHODS}

Valproic acid was Gift sample from Global Pharma, Mumbai, India. Carboxymethyl chitosan was procured from Indian Seafood, Kerala, India. Calcium chloride was purchased from the Sigma Aldrich, Mumbai, India. SH-SY5Y cell line was purchased from the NCCS, Pune. All the other chemicals used were of analytical grade. 


\section{Compatibility Studies}

\section{Differential Scanning Calorimetry}

Differential Scanning Calorimetry (DSC) thermo grams were determined to analysis the thermal behaviour of VPA, CMC, physical mixture and the optimized formulation for the compatibility. Samples were sealed in a standard aluminium pan then heated up to $20-400^{\circ} \mathrm{C}$. The rate of heat was $10^{\circ} \mathrm{C} / \mathrm{min}$. The nitrogen purging rate of dry was $30 \mathrm{ml} / \mathrm{min}$. A blank pan used as a reference. The thermo grams acquired from the DSC were utilized for finding the compatibility. ${ }^{8,9}$

\section{Formulation of Valproic acid loaded carboxymethyl chitosan Polymeric nanoparticles}

Ionic relation strategy was the method in the preparation of CMC-PNPs. Optimized concentration of CMC was dissolved in water and stirred overnight at 700 RPM and filtered using a muslin cloth. The Drug was pre-incubated in the polymer solution overnight. The High turbidity of the formulation was neutralized by $\mathrm{Hcl}$ added drop wise. $\mathrm{CaCl}_{2}$ as a cross-linking agent of optimized concentrations was prepared poured drop wise in CMC solution, with a syringe under stirring until the turbidity formed. The prepared dispersion was permitted to stabilize by a magnetic stirrer for overnight at $4^{\circ} \mathrm{C}$. The formulation was centrifuged and the PNPs were lyophilized. The optimization of the process was done using the DOE method. ${ }^{10}$

\section{Optimization of Polymeric Nan particle}

The optimization of the formulation was done by using Design-Expert ${ }^{\circledR}$ Version 7.0.0 Software BoxBehnken design. All the main factors values were given in the optimum ranges from high to low values. The

\section{Table 1: Factor level for optimization of O-CMC} Polymeric nanoparticles.

\begin{tabular}{|c|c|c|c|}
\hline \multicolumn{2}{|l|}{ Independent Variables } & \multicolumn{2}{|c|}{ Dependant Variables } \\
\hline Actual values & $\begin{array}{l}\text { Coded } \\
\text { values }\end{array}$ & $\begin{array}{l}\text { Actual } \\
\text { Values }\end{array}$ & $\begin{array}{l}\text { Coded } \\
\text { values }\end{array}$ \\
\hline \multirow[t]{3}{*}{ Polymer Concentration (\%) } & \multirow[t]{3}{*}{ A } & 0.10 & -1 \\
\hline & & 0.30 & 0 \\
\hline & & 0.50 & +1 \\
\hline \multirow{3}{*}{$\begin{array}{l}\text { Calcium chloride } \\
\text { Concentration (\%) }\end{array}$} & \multirow[t]{3}{*}{ B } & 0.20 & -1 \\
\hline & & 0.40 & 0 \\
\hline & & 0.60 & +1 \\
\hline \multirow[t]{3}{*}{ Stirring time (min.) } & \multirow[t]{3}{*}{ C } & 70 & -1 \\
\hline & & 130 & 0 \\
\hline & & 190 & +1 \\
\hline
\end{tabular}

effect of the independent variable which was Polymer concentration (\%), Calcium chloride concentration (\%) and sonication time (min.) was observed. The responses PS, EE and PDI were checked. The Box-Behnken design was used to see the effects of the independent variable on the dependent variables. According to Box-Behnken design 17 runs were performed. Factor level for optimized polymeric nanoparticle was shown in Table 1. The response was observed for each experimental quadratic and interactive equation generated by the software. 3D response surface plots were plotted to study the effects of both main and interaction on independent variables. ${ }^{11}$

\section{Characterization of Valproic acid loaded Polymeric Nan particle}

\section{Determination of Particle size and Zeta Potential}

Characterization of PS and ZP were done by Zeta sizernano series ${ }^{\circledR}$ Malvern instrument, UK at a wavelength of $633 \mathrm{~nm} \cdot{ }^{12,13}$

\section{Calculation of the Entrapment Efficiency of VPA in PNPs}

Entrapment efficiency of the formulation was measured after centrifuged at 7500 RPM for $1 \mathrm{hr}$. The NPs were collected and dissolved into $5 \mathrm{ml}$ of buffer solution and make up to $10 \mathrm{ml}$. After that samples were filtered through the $0.22 \mu \mathrm{m}$ membrane filter and estimated using HPLC method at $219 \mathrm{~nm}$ using PDA detector. The EE were calculated using equation 1.

$$
\text { Entrapment Efficiency }=\frac{\begin{array}{l}
\text { Amount of Drug in } \\
\text { nanoparticle }
\end{array}}{\begin{array}{l}
\text { Amount of Drug in } \\
\text { formulation }
\end{array}} \times 100
$$$$
\text { Equation..... (1) }
$$

\section{Scanning electron microscopy for the study of surface morphology}

Surface morphology was studied using scanning electron microscopy. Examine samples was diluting in deionized water to get a concentration. In the sample holder, the sample was kept and was subjected to vacuum drying. Samples were measured after coating with gold.

\section{In vitro drug release study}

The dialysis bag technique was applied for in vitro drug release of polymeric nanoparticles. Specifically weighed the amount of lyophilized sample was suspended in $1 \mathrm{ml}$ of PBS and was put in dialysis sack (10,000-12,000 Da). 
The sack was settled at both the closes and submerged in $200 \mathrm{ml}$ of phosphate buffer at the $\mathrm{pH} 7.4$ with continuous stirring at $100 \pm 5$ rotations per minute in a shaker maintaining at $37.5^{\circ} \mathrm{C}$. At specific time intervals $(0$, $1,5,10,15,25,38,48 \mathrm{hr}$ ), aliquots were pipette out from the release medium and sink condition was maintained. The in vitro release analysis was performed utilizing HPLC method. The detection was done at $219 \mathrm{~nm}$ using PDF detector(1). The column was $\mathrm{C}_{18}$ and the mobile phase ratio was Acetonitrile: Water (1:1) with flow rate $1 \mathrm{ml} / \mathrm{min}$.

In vitro drug release holds an important position in the process of developing a drug. To know about the drug release mechanism, the released data was applied into various kinetics models such as zero order, First order, Higuchi's model, Korsmeyer-Peppas and Hixon Crowel model.

\section{Stability study}

The stability testing study is performed by the Freeze-thaw cycle technique. The study was finished by exposing the sample to frigid temperature $\left(-10^{\circ} \mathrm{C}\right)$ for the one day and after that kept at room temperature for again one day. After that, the Formulation was put at a high temperature around $45^{\circ} \mathrm{C}$ for one day. After that, the sample was again put at room temperature for one day. The formulation was investigated for altogether changes for organoleptic properties, PS and \%EE. On the off chance that, after 3 cycles of testing, if no critical changes are found the stability of product can be assured.

\section{In vitro Cytotoxicity Studies}

MTT assay is one of the effective assay methods to study the cytotoxicity of the formulation. The process was done by seeded the cells in 96 well plated $\left(1 \times 10{ }^{5}\right.$ cells/well $)$ and incubated for $48 \mathrm{hr}$ in DMEM medium with different concentration of the drug $(1,10,50,100$ and $200 \mu \mathrm{g} / \mathrm{mL})$ and the optimized VPA loaded PNPs. $20 \mu \mathrm{L}$ of MTT reagent $(5 \mathrm{mg} / \mathrm{mL})$ was added. The culture medium was removed and $150 \mu \mathrm{L}$ of dimethyl sulfoxide (DMSO) was added to each well. The optical density (OD) was evaluated using Multi-Mode Microplate-Reader at $490 \mathrm{~nm}$. The process was performed in triplicate. The half maximal inhibitory concentration $\left(\mathrm{IC}_{50}\right)$ of each group and the formulation were calculated. ${ }^{14}$

\section{Nasalcilio Toxicity Study}

Nasal Ciliotoxicity study was performed by isolating mucosa from goat nasal. It was collected from the slaughterhouse and kept into the PBS pH 6.4 buffer solutions. Isolated nasal goat mucosa cut into the 5 pieces and after that pieces dipped for $2 \mathrm{hr}$ into a differentsolution such as PBS pH $6.4(1 \mathrm{mg} / \mathrm{ml})$,
Polymeric nanoparticle (Blank), VPA loaded PNPs, Pure drug (valproic acid), Isopropyl Alcohol (IPA) as a positive control. Negative control was PBS solution at $\mathrm{pH} 7.4$ and Positive control was IPA. After that, each sample was washed with distilled water and kept in formalin solution $(10 \%)$ for preservation until further investigation. The samples were examined and stained by $\mathrm{H}$ and $\mathrm{E}$ and analysed by the pathologist using the optical magnifying instrument. ${ }^{15}$

\section{RESULTS AND DISCUSSION \\ Formulation of VPA-Loaded PNPs}

VPA loaded O-CMC $\mathrm{CaCl}_{2}$ cross linked nanoparticles was formulated using ionic gelation technique. The mechanism of formulation is shown in Figure 2.

\section{Box-Behnken Model for the optimization of the formulation ${ }^{16}$}

For the Optimization of formulation Box- Behnken design was utilized. Total 17 runs were performed. All the Reponses data are given in Table 2. The values from low to high of responses are in the range: Y1 particle size $(220$ - $590 \mathrm{~nm})$, Y2 Entrapment efficiency (42\% $-79 \%)$ and Y3 Polydispersity Index (0.355 - 0.769). The ratio was from minimum to maximum was for the
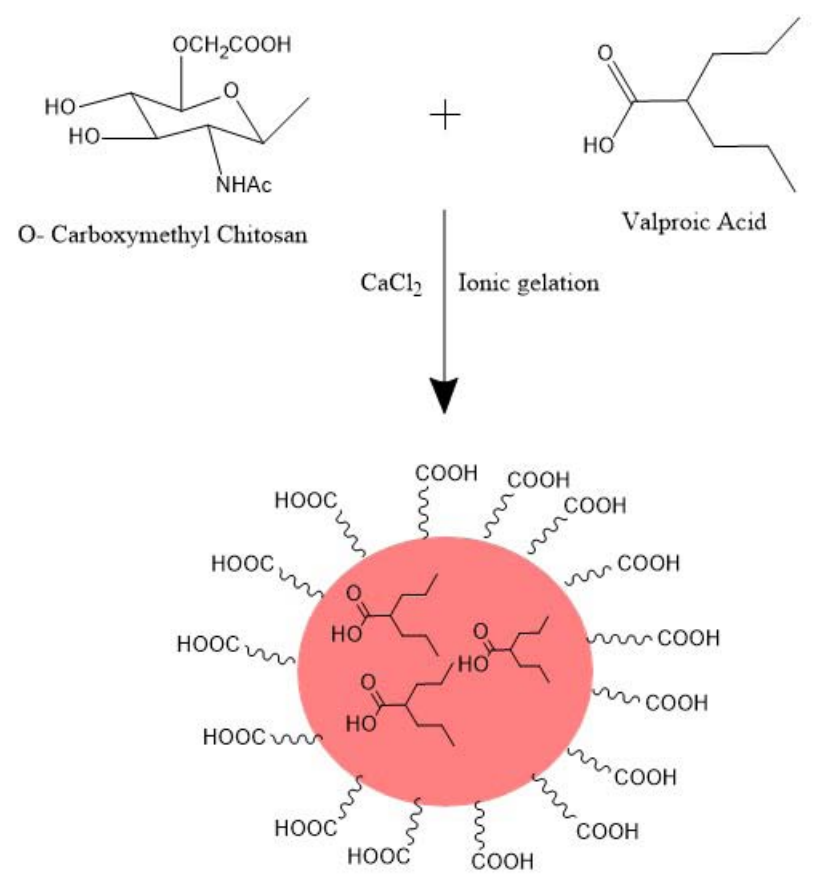

VPA-OCMC-NPs

Figure 2: Mechanism of Valproic acid loaded Carboxymethyl Chitosan Nanoparticles. 


\begin{tabular}{|c|c|c|c|c|c|c|}
\hline Run & $\begin{array}{c}\text { Polymer } \\
\text { concentration } \\
\text { (\%) }\end{array}$ & $\begin{array}{c}\text { Calcium chloride } \\
\text { concentration } \\
(\%)\end{array}$ & $\begin{array}{l}\text { Stirring time } \\
\quad(\min .)\end{array}$ & $\begin{array}{c}\text { Response } 1 \\
\text { Particle size }(\mathrm{nm})\end{array}$ & $\begin{array}{c}\text { Response } 2 \\
\text { Entrapment } \\
\text { efficiency (\%) }\end{array}$ & $\begin{array}{c}\text { Response } 3 \\
\text { Stirring time } \\
\text { (Min.) }\end{array}$ \\
\hline 1 & 0.30 & 0.60 & 190 & 284.8 & 42.54 & 0.435 \\
\hline 2 & 0.30 & 0.20 & 190 & 539.3 & 85.62 & 0.726 \\
\hline 3 & 0.50 & 0.60 & 130 & 300.5 & 48.25 & 0.599 \\
\hline 4 & 0.30 & 0.40 & 130 & 371.3 & 56.35 & 0.607 \\
\hline 5 & 0.50 & 0.40 & 70 & 220.0 & 38.59 & 0.403 \\
\hline 6 & 0.30 & 0.40 & 130 & 271.3 & 40.35 & 0.401 \\
\hline 7 & 0.10 & 0.20 & 130 & 425.5 & 79.33 & 0.713 \\
\hline 8 & 0.30 & 0.40 & 130 & 371.3 & 58.35 & 0.769 \\
\hline 9 & 0.30 & 0.40 & 130 & 371.3 & 62.35 & 0.669 \\
\hline 10 & 0.10 & 0.40 & 70 & 312.6 & 54.64 & 0.762 \\
\hline 11 & 0.30 & 0.60 & 70 & 441.8 & 80.90 & 0.885 \\
\hline 12 & 0.10 & 0.60 & 130 & 329.6 & 55.29 & 0.625 \\
\hline 13 & 0.30 & 0.40 & 130 & 371.3 & 59.35 & 0.669 \\
\hline 14 & 0.30 & 0.20 & 70 & 398.2 & 70.29 & 0.595 \\
\hline 15 & 0.10 & 0.40 & 190 & 278.6 & 45.68 & 0.359 \\
\hline 16 & 0.50 & 0.20 & 130 & 498.3 & 82.92 & 0.355 \\
\hline 17 & 0.50 & 0.40 & 190 & 350.4 & 65.47 & 0.660 \\
\hline
\end{tabular}

response Y1, Y2 and Y3 is 2.45, 2.21 and 2.49. Polynomial model which are, Quadratic and Interactive model were fitted into the experimental data. 3 tests mainly the sequential model sum of squares, lack of fit test and model summary statistics were carried out to conclude the adequacy of the model shown in Table 3.

ANOVA data confirms the significance of model. All the details of the ANOVA are given in the Table 4. The $F$ value of responses $\mathrm{Y} 1, \mathrm{Y} 2$ and $\mathrm{Y} 3$ was $7.09,3.99$ and 3.62 which implies that model is significant.

Predicted $R^{2}$ value, Adjusted $R^{2}$ value and Adequate precision values for the responses were shown into the Table 5. Predicted $R^{2}$ indicated that model has predicted the response well. Adequate precision measures the signal to noise ratio. A ratio is greater than 4 is desirable. The ration obtained was 10.600 indicates the adequate signal.

\section{Regression model for Particle Size}

Effect of the Individual parameter on the VPA loaded polymeric nanoparticle design was generated by the software using Box-behnken design. The PS range was found to be 220 to $590 \mathrm{~nm}$. The coded term equation 2 is for the PS of the optimized formulation was generated by the design is:

Particle size $=+351.30+2.86 * \mathrm{~A}-63.07 * \mathrm{~B}+10.06 * \mathrm{C}$ $-25.48 * \mathrm{~A} * \mathrm{~B}+41.10 * \mathrm{~A} * \mathrm{C}-74.52 * \mathrm{~B} * \mathrm{C}-44.23 \mathrm{~A}^{2}+$ $81.40 * \mathrm{~B}^{2}-16.67 * \mathrm{C}^{2}$
In these equation positive values is showing the synergistic impression on the optimization, while a negative value leads an antagonistic impression between the factors and the responses. The model $F$ value was 7.09. This model was significant. The probability F- value was $0.86 \%$. In this model $\mathrm{B}, \mathrm{BC}$ and $\mathrm{B}^{2}$ was substantial model terms. This equation indicating that, Polymer concentration and stirring time had the positive effect and $\mathrm{CaCl}_{2}$ concentration had the negative effect on the PS. This model is indicating that $\mathrm{CaCl}_{2}$ concentration was the most significant factor for the PS.

\section{Effect of process parameter on the Particle Size}

In these graphs (Figure 3), it is describing that the higher concentration of polymer will leads to higher the particle size. Here, polymer concentration depends on the particle size diameter which is the most influencing parameter which is shown in the Figure [A]. In case of $[B]$, it is showing that if stirring time is increasing, particle size is also increasing but with high concentration of polymer giving the optimize particle size. And in case of [C], higher concentration of calcium concentration is giving the optimum particle size.

Higher the concentration of the polymer enhances the viscosity which responsible for the formation of the larger droplets. The influence of CMC concentration on the mean hydrodynamic diameter of PS can be associated to volume occupied by the polymer chain in 


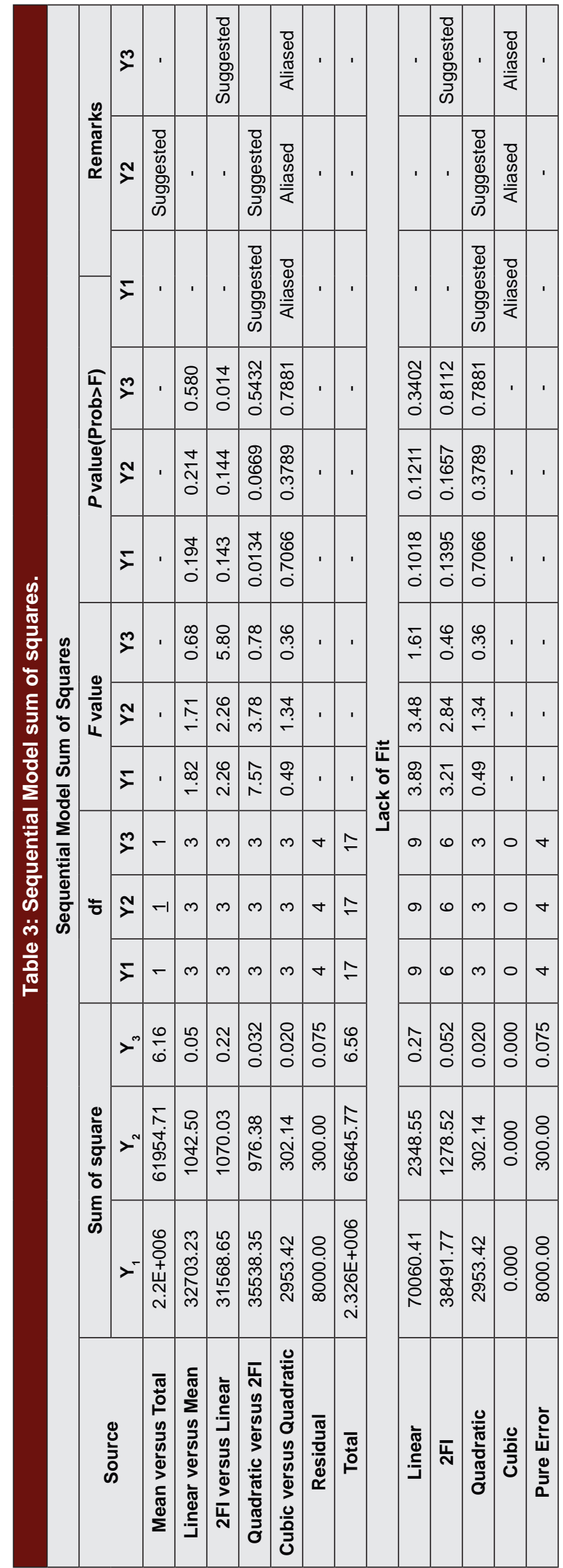

\begin{tabular}{|c|c|c|c|c|c|c|c|c|c|c|c|c|c|c|c|}
\hline & 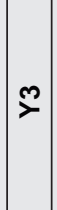 & 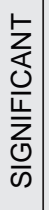 & & & & ' ' & & & & & & & 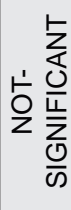 & & \\
\hline 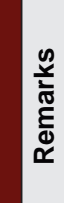 & $\underset{>}{ }$ & $\left|\begin{array}{c}\frac{z}{u} \\
\frac{0}{u} \\
\frac{\bar{\nu}}{v} \\
\frac{0}{\omega}\end{array}\right|$ & & & & ' & ' & & & ' & ' & & 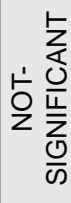 & & \\
\hline & $F$ & 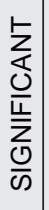 & & & & ' & , & & & ' & ' & & 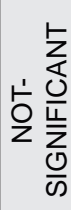 & & , \\
\hline$\pi$ & $\stackrel{m}{\nu}$ & $\begin{array}{c}\infty \\
\stackrel{\infty}{1} \\
\tilde{ల} \\
0 \\
0\end{array}$ & 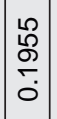 & $\left|\begin{array}{l}-1 \\
\hat{\infty} \\
0 \\
0\end{array}\right|$ & $\mid \begin{array}{c}-1 \\
\stackrel{n}{-} \\
-1 \\
0\end{array}$ & $\mid \begin{array}{c}m \\
\stackrel{-}{7} \\
\overrightarrow{-} \\
0\end{array}$ & $\begin{array}{l}0 \\
10 \\
0 \\
0 \\
0 \\
0\end{array}$ & 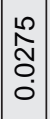 & ' & ' & . & ' & $\begin{array}{l}\underset{7}{7} \\
\underset{0}{0} \\
0\end{array}$ & & ' \\
\hline $\begin{array}{l}\frac{0}{0} \\
\frac{0}{2} \\
\frac{\partial}{0}\end{array}$ & \} $&{\begin{array}{l}\infty \\
o \\
\text { ठ } \\
\dot{0}\end{array}} &{\begin{array}{|l|} \\
\Omega \\
\delta \\
\delta \\
0 \\
\end{array}} &{\begin{array}{|c|} \\
0 \\
0 \\
0 \\
0 \\
\end{array}} &{\begin{array}{l}-7 \\
i \\
\infty \\
0 \\
0\end{array}} &{\mid \begin{array}{l}n \\
0 \\
\infty \\
1 \\
0 \\
0\end{array}} &{\mid \begin{array}{l}0 \\
\delta \\
0 \\
0 \\
0\end{array}} &{\text { 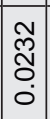 }} &{\begin{array}{l}\hat{L} \\
\stackrel{N}{ } \\
0 \\
0\end{array}} &{\begin{array}{l}-\vec{m} \\
\stackrel{-}{0} \\
\dot{0}\end{array}} &{\text { 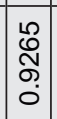 }} &{\text { ' }} &{\text { 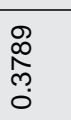 }} &{ } &{\text {, }} \\
{\hline} &{\overrightarrow{>}} &{\begin{array}{l}0 \\
\infty \\
0 \\
0 \\
0\end{array}} &{\text { 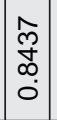 }} &{\left|\begin{array}{c}0 \\
\tilde{D} \\
0 \\
0 \\
0\end{array}\right|} &{\text { 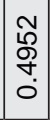 }} &{\mid \begin{array}{c}\hat{\infty} \\
\tilde{N} \\
\stackrel{0}{0}\end{array}} &{\begin{array}{l}0 \\
0 \\
0 \\
0 \\
0\end{array}} &{\begin{array}{l}0 \\
0 \\
8 \\
0 \\
0\end{array}} &{\text { 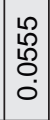 }} &{\begin{array}{l}\mathscr{0} \\
\text { ర్ } \\
\text { Oे } \\
\dot{0}\end{array}} &{\begin{array}{c}\hat{n} \\
\stackrel{7}{+} \\
0 \\
0\end{array}} &{ } &{\text { 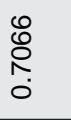 }} &{ } &{\text {, }} \\
{\hline} &{\stackrel{m}{>}} &{\begin{array}{l}\tilde{O} \\
\stackrel{\rho}{\sim}\end{array}} &{\left|\begin{array}{c}N \\
\widetilde{T} \\
\dot{\gamma}\end{array}\right|} &{\begin{array}{l}\stackrel{\sim}{N} \\
O\end{array}} &{\text { 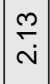 }} &{\mid \begin{array}{l}\hat{i} \\
\mathrm{~N}\end{array}} &{\left|\begin{array}{c}\infty \\
i \\
\infty \\
\infty\end{array}\right|} &{\mid \begin{array}{l}0 \\
\varrho \\
0 \\
0\end{array}} &{\text {. }} &{\text { ' }} &{\text {. }} &{\text { ' }} &{\begin{array}{l}\text { o } \\
\text { o }\end{array}} &{ } &{\text {, }} \\
{\hline \text { 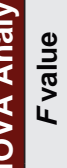 }} &{\text { \ }} &{\begin{array}{l}\text { बे } \\
\text { ले }\end{array}} &{\text { 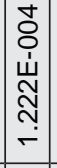 }} &{\text { 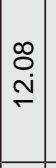 }} &{\mid \begin{array}{l}\infty \\
\tilde{\tilde{~}} \\
0 \\
0\end{array}} &{\mid \begin{array}{c}m \\
\tilde{m} \\
0\end{array}} &{\begin{array}{c}\tilde{N} \\
\tilde{\omega}\end{array}} &{\mid \begin{array}{c}\infty \\
\infty \\
\infty \\
\infty\end{array}} &{\mid \begin{array}{l}N \\
N \\
0\end{array}} &{\begin{array}{l}8 \\
0 \\
0 \\
-1\end{array}} &{\text { 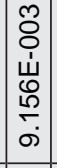 }} &{ } &{\underset{\sim}{\stackrel{\Xi}{-}}} &{ } &{\text { ' }} \\
{\hline} &{\overrightarrow{>}} &{\begin{array}{l}\stackrel{2}{2} \\
\stackrel{\Gamma}{ }\end{array}} &{\mid \begin{array}{l}\mathcal{Y} \\
\text { Oे }\end{array}} &{\text { 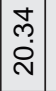 }} &{\mid \begin{array}{l}\tilde{\omega} \\
\stackrel{0}{0} \\
\dot{0}\end{array}} &{\left|\begin{array}{l|}0 \\
\hdashline \\
-i\end{array}\right|} &{\begin{array}{l}\tilde{m} \\
\dot{\sigma}\end{array}} &{\text { 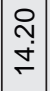 }} &{\text { 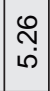 }} &{\begin{array}{l}\infty \\
\infty \\
\\
-1\end{array}} &{\begin{array}{l}\stackrel{L}{\Lambda} \\
0 \\
\dot{0}\end{array}} &{\text {. }} &{\stackrel{g}{\square}} &{\text { ' }} &{\text {. }} \\
{\hline} &{\stackrel{m}{\nu}} &{0} &{\rightarrow} &{-1} &{-1} &{\rightarrow} &{-1} &{-1} &{1} &{1} &{\text { ' }} &{\text { 우 }} &{0} &{\nabla} &{\stackrel{\leftrightarrow}{-1}} \\
{\hline \text { tั }} &{\underset{\searrow}{\mathbf{N}}} &{\text { の }} &{-1} &{-1} &{-1} &{-1} &{-1} &{-1} &{-1} &{-1} &{-1} &{\wedge} &{m} &{\nabla} &{\underset{-1}{0}} \\
{\hline} &{\vec{\gamma}} &{\text { a) }} &{\rightarrow} &{\neg} &{-1} &{-1} &{\text { - }} &{\text { 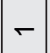 }} &{-1} &{-1} &{-1} &{\wedge} &{m} &{\nabla} &{\underset{-1}{0}} \\
{\hline \text { 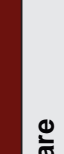 }} &{\stackrel{m}{>}} &{\begin{array}{l}\infty \\
\stackrel{0}{0} \\
0\end{array}} &{\text { 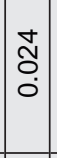 }} &{\text { 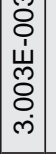 }} &{\begin{array}{l}\hat{N} \\
0 \\
0 \\
0\end{array}} &{\text { 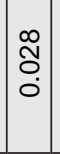 }} &{\begin{array}{l}\overrightarrow{7} \\
0 \\
0\end{array}} &{\mid \begin{array}{l}0 \\
0 \\
0 \\
0 \\
0\end{array}} &{ } &{\text {. }} &{1} &{\begin{array}{c}m \\
\hdashline \\
0\end{array}} &{\begin{array}{l}\text { బิ } \\
\text { O. }\end{array}} &{ } &{\text { 움 }} \\
{\hline \begin{array}{l}\overline{0} \\
\overline{0} \\
\Xi\end{array}} &{\text { 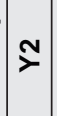 }} &{\begin{array}{l}\sigma \\
\infty \\
\infty \\
\infty \\
0 \\
m\end{array}} &{\text { - }} &{\begin{array}{l}\tilde{N} \\
\tilde{D} \\
\tilde{ల} \\
\hdashline\end{array}} &{\begin{array}{l}0 \\
\stackrel{0}{n} \\
\dot{m}\end{array}} &{\begin{array}{c}\stackrel{L}{N} \\
\stackrel{\infty}{N} \\
\stackrel{0}{N}\end{array}} &{\left|\begin{array}{c}m \\
\sim \\
-\vec{j} \\
\tilde{m}\end{array}\right|} &{\text { 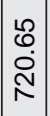 }} &{\begin{array}{c}\text { กิ } \\
\text { - } \\
-1\end{array}} &{\text { 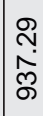 }} &{\begin{array}{c}0 \\
2 \\
0\end{array}} &{\mid \begin{array}{l}\vec{J} \\
\stackrel{\sim}{i} \\
\tilde{D} \\
0\end{array}} &{\text { 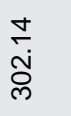 }} &{ } &{\begin{array}{l}\text { L } \\
\text { - } \\
\text { Oे } \\
\text { }\end{array}} \\
{\hline} &{\overrightarrow{>}} &{\begin{array}{l}\tilde{N} \\
0 \\
0 \\
0 \\
\delta \\
0\end{array}} &{\text { 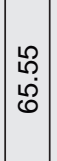 }} &{\begin{array}{c}\vec{J} \\
0 \\
N \\
\infty \\
0 \\
m \\
m\end{array}} &{\mid \begin{array}{l}\tilde{n} \\
0 \\
0 \\
0 \\
\infty \\
\end{array}} &{\text { 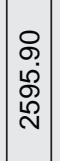 }} &{\mid \begin{array}{l}0 \\
0 \\
0 \\
h \\
0 \\
0\end{array}} &{\text { 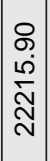 }} &{\text { 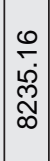 }} &{\begin{array}{l}\infty \\
\stackrel{\infty}{\infty} \\
\infty \\
\infty \\
\stackrel{\infty}{\sim} \\
\sim\end{array}} &{\text { 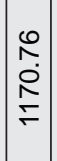 }} &{\text { 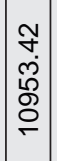 }} &{\begin{array}{l}\text { ָे } \\
\stackrel{N}{\mathscr{N}} \\
\text { N }\end{array}} &{\begin{array}{l}8 \\
\dot{8} \\
8 \\
\varnothing \\
\infty\end{array}} &{\text { 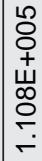 }} \\
{\hline \text { 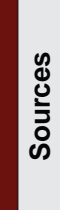 }} &{ } &{\begin{array}{l}\overline{\mathbf{d}} \\
\frac{0}{\Sigma}\end{array}} &{\text { 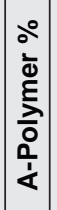 }} &{\text { 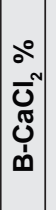 }} &{\text { 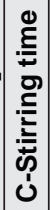 }} &{\stackrel{m}{<}} &{\begin{array}{l}0 \\
<\end{array}} &{\begin{array}{l}0 \\
\end{array}} &{\stackrel{\sim}{\ll}} &{\tilde{\text { }}} &{\text { U }} &{\text { 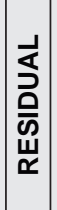 }} &{\text { 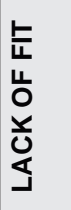 }} &{\text { 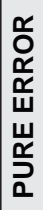 }} &{\text { 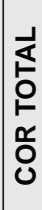 }} \\
$\hline
\end{tabular}


Table 5: Regression terms for the response.

\begin{tabular}{|c|c|c|c|c|}
\hline Response & C.V. \% & $\begin{array}{c}\text { Predicted } \\
\boldsymbol{R}^{\mathbf{2}}\end{array}$ & $\begin{array}{c}\text { Adjusted } \\
\boldsymbol{R}^{\mathbf{2}}\end{array}$ & $\begin{array}{c}\text { Adequate } \\
\text { Precision }\end{array}$ \\
\hline Particle size & 10.96 & 0.4605 & 0.7740 & 10.600 \\
\hline $\begin{array}{c}\text { Entrapment } \\
\text { Efficiency }\end{array}$ & 15.36 & 0.4367 & 0.6271 & 7.389 \\
\hline $\begin{array}{c}\text { Polydispersity } \\
\text { Index }\end{array}$ & 18.71 & 0.1498 & 0.4952 & 6.397 \\
\hline
\end{tabular}

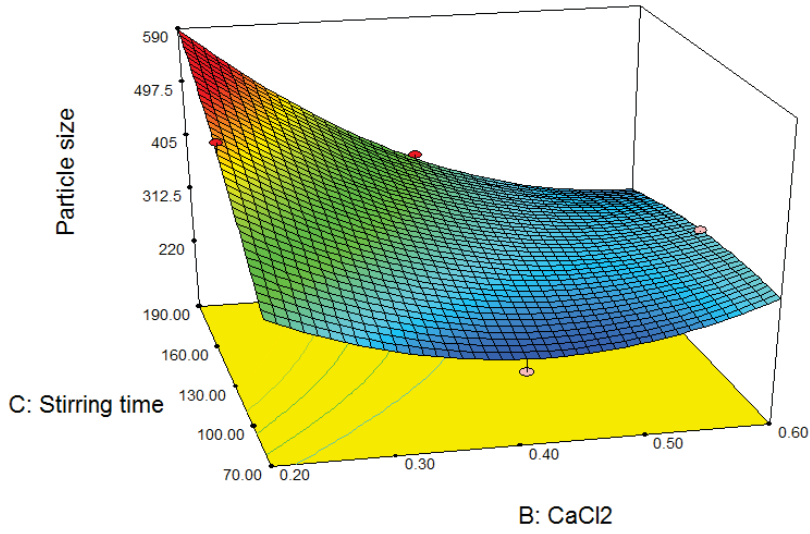

Figure 3: 3D Surface plots of showing effect of [A] Polymer concentration, $[\mathrm{B}]$ Calcium chloride concentration and [C] stirring time on the Particle size.

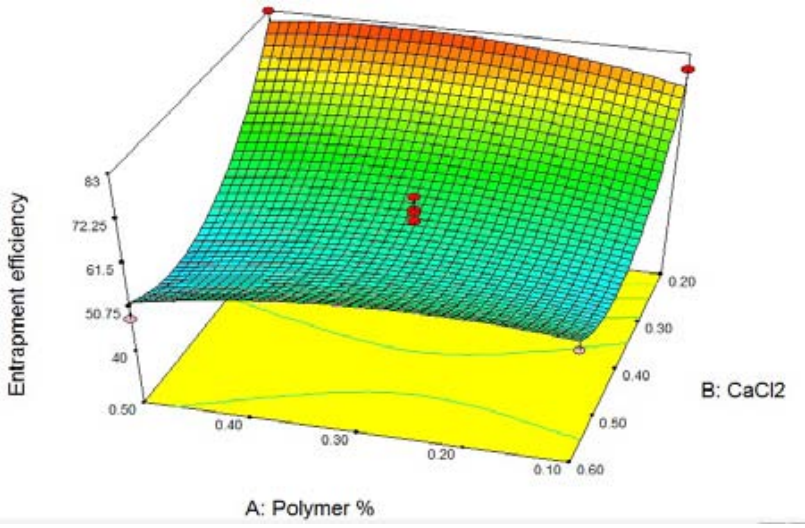

Figure 4: 3D Surface plots of showing effect of [A] Polymer concentration, $[\mathrm{B}]$ Calcium chloride concentration and

[C] stirring time on the Entrapment efficiency.

solution. The volume engaged by a polymer may be due to its concentration and intrinsic viscosity, which reflects the degree of space occupancy of the polymer chain.

\section{Regression model for Entrapment Efficiency}

Effect of the Individual parameter on the VPA loaded PNPs design was generated by the software using Boxbehnken design. The Entrapment Efficiency range was found to be $42 \%$ to $79 \%$. The coded term equation 3 is for the Entrapment Efficiency of the optimized formulation was generated by the design is:
Entrapment Efficiency $=+55.35+0.036 * \mathrm{~A}-11.40 * \mathrm{~B}$ $-0.64 * \mathrm{C}-2.66 * \mathrm{~A} * \mathrm{~B}+8.96 * \mathrm{~A} * \mathrm{C}-13.42 * \mathrm{~B} * \mathrm{C}-$ $3.82 * \mathrm{~A}^{2}+14.92 * \mathrm{~B}^{2}-0.43 * \mathrm{C}^{2} \quad$ Equation...... (3)

Here, the equations are clearly showing that model is quadratic model. The model $F$ value was 3.99 , which is representing the significant model. The probability $\mathrm{F}$ value was $4.08 \%$. In this model $\mathrm{B}, \mathrm{BC}$ and $\mathrm{B}^{2}$ are important model terms. This equation is showing that Polymer concentration is had the positive effect, calcium chloride concentration and stirring time had the negative effect.

\section{Effect of process parameter on Entrapment Efficiency}

The addition of VPA with CMC was interaction between the polymer and drug. The drug was entrapped within the polymeric nanoparticles by cross linking using $\mathrm{CaCl}_{2}$. The initial addition helped for enhancement of \%EE of Valproic acid. So the DOE indicated that enhancement in the polymer concentration enhance drug entrapment. In these plots (Figure 4), it is indicating that $\mathrm{CaCl}_{2}$ concentration and stirring time is most significant factor for the entrapment efficiency of VPA into the polymer.

\section{Regression Model for Polydispersity Index}

Effect of the Individual parameter on the VPA loaded PNPs design was generated by the software using Box-behnken design. The Polydispersity index range was found to be 0.355 to 0.769 . The coded terms equation 4 is for the Polydispersity Index of the optimized formulation was generated by the design is:

$$
\begin{array}{lr}
\mathrm{PDI}=+0.60-0.055^{*} \mathrm{~A}+0.019 * \mathrm{~B}-0.058 * \mathrm{C}+0.083 * \\
\mathrm{~A} * \mathrm{~B}+0.17 * \mathrm{~A} * \mathrm{C}-0.15^{*} \mathrm{~B} * \mathrm{C} \quad \text { Equation...... (4) }
\end{array}
$$

The model was found to be significant. This model is showing 2FI (interactive model) equation. The $F$ value was 3.62 and probability $F$ value was found to be $3.58 \%$. In this model AC and BC were important model terms. This equation is showing that Polymer concentration and calcium chloride concentration had positive effect and stirring time is having the negative effect.

\section{Effect of process parameters on Polydispersity Index}

As we increase the concentration of CMC the negative charge gets increased and if increases the concentration of $\mathrm{CaCl}_{2}$ the positive charge is get increase these is showing the interaction. So that is the reason this model (Figure 5) is showing the Interaction model (2FI). 


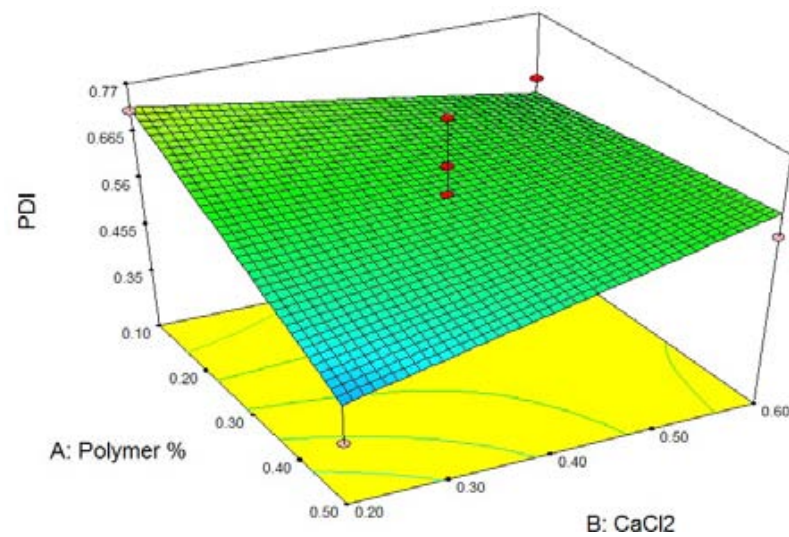

Figure 5: 3D Surface plots of showing effect of [A] Polymer concentration, $[B]$ Calcium chloride concentration and [C] stirring time on the Polydispersity Index.

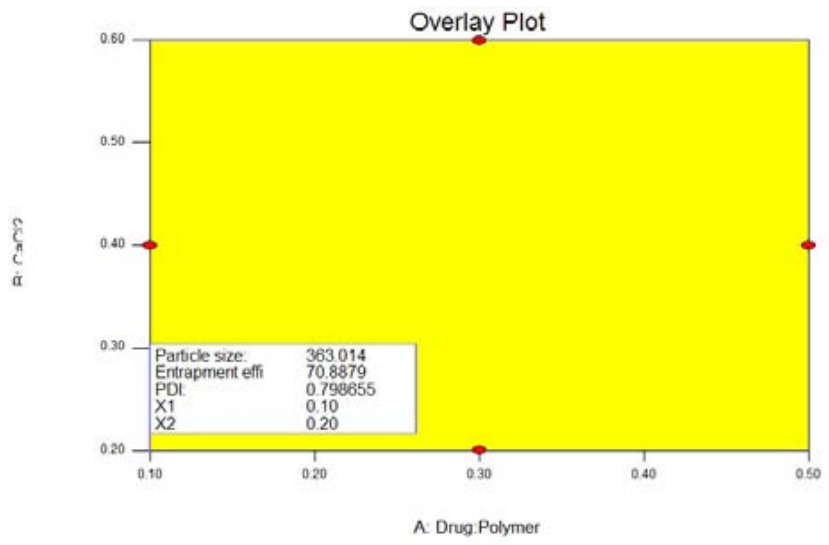

Figure 6: Overlay plot for optimized parameters of formulation.

\begin{tabular}{|c|c|c|c|c|c|c|}
\hline & 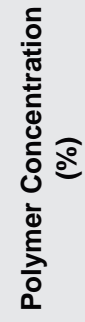 & 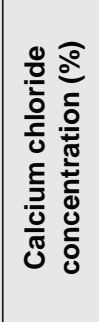 & 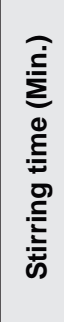 & 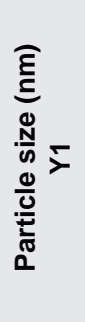 & 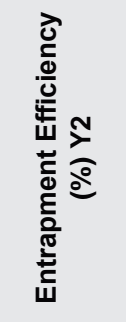 & 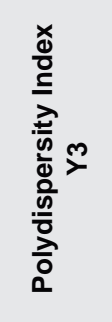 \\
\hline Expected & $0.5 \%$ & $0.2 \%$ & 130 & 363 & 70 & 0.796 \\
\hline (Predicted) & $0.5 \%$ & $0.2 \%$ & 130 & 384 & 68 & 0.675 \\
\hline Error \% & & & & $5.4 \%$ & $-2.94 \%$ & $-8.16 \%$ \\
\hline
\end{tabular}

\section{Optimization of Process Parameters}

The optimized formulation generated by the software dependent on the desirability was found at 0.10 and 0.20 level of $\mathrm{X} 1$ and $\mathrm{X} 2$ respectively. The determined desirability factor for the offered formulation was 0.899 , demonstrating the reasonableness of the designed factorial model. The result of dependent variables

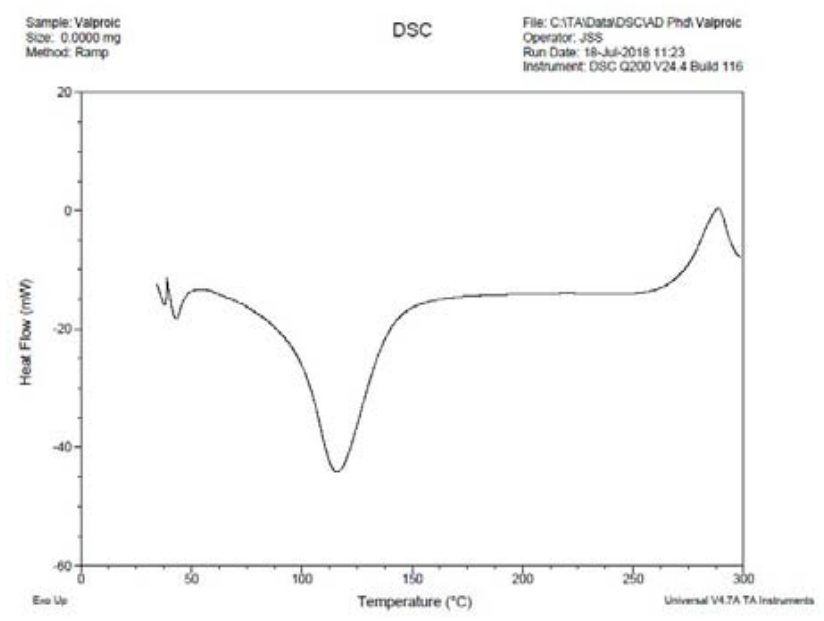

Figure 7: Thermograms of Valproic acid.

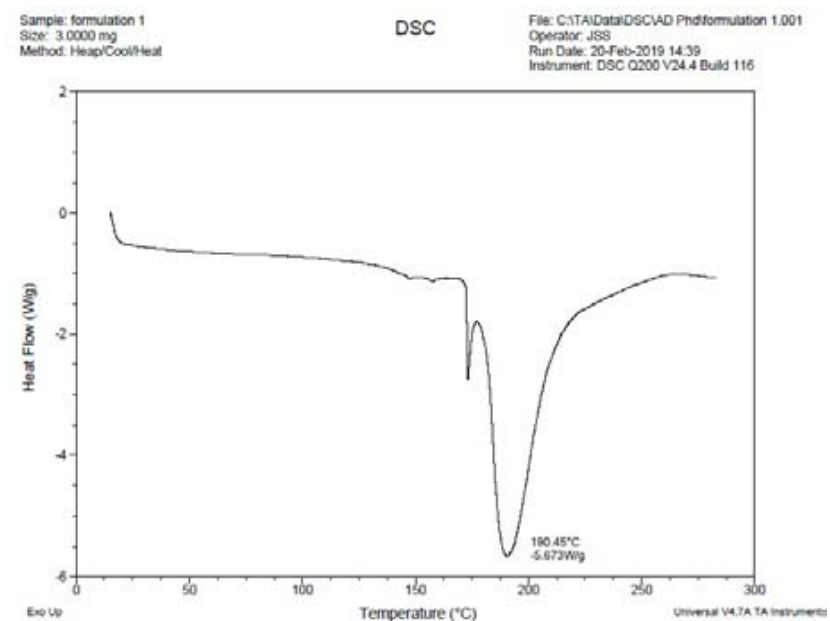

Figure 8: DSC Thermograms of Formulation.

from the software was observed to be $363 \mathrm{~nm}$ for particle size, $70.88 \%$ for entrapment efficiency and 0.79 is Polydispersity index. Overlay plot for optimized formulation is shown in Figure 6.

For Expected values of response Y1, Y2 and Y3 were $363.01 \mathrm{~nm}, 70.88 \%$ and 0.79 . By using these values one batch is prepared. The actual values of Y1, Y2 and Y3 were found to be $384 \mathrm{~nm}, 68 \%$ and 0.675 respectively, it showed that the VPA loaded PNPs were in close agreement with the predicted values. In the Table 6 predicted and actual responses of optimized formulation is shown.

\section{Compatibility study}

\section{Differential scanning calorimeter}

The DSC graph of VPA and formulation are shown in Figure 7, 8. The Differential scanning calorimeter (DSC) thermo grams of polymer carboxymethyl chitosan demonstrated a broad peak indicating polymeric nature. The disappearance of the drug peak into the 
formulation clearly indicating the encapsulation of the drug in the polymer matrix as well as uniform dispersion of the drug into the amorphous state in the polymeric Nano formulation. Consequently, the assessment of the thermo grams clearly showed that there was no physical interaction among the carboxymethyl chitosan and the valproic acid in the prepared formulation.

\section{Scanning Electron Microscopy}

SEM studies were performed to ensure the uniformity of particle shape and size. The scanning electron microscopy photograph of valproic acid loaded polymeric nanoparticle shows that non-spherical structure this is likely due to the fact that as a particles decrease they are liable to aggregates due to their high specific surface energy so there is no clear spherical structure obtained as shown in Figure 9.

\section{Evaluation of nanoparticle}

\section{In vitro drug release study and release kinetics}

The in vitro release studies were performed at the $\mathrm{pH}$ 7.4 which was equivalent to that of brain $\mathrm{pH}$. VPA is an acidic drug. The drug got entrapped into the polymeric matrix in turn enhanced the bioavailability and absorption of drug. The drug release was observed for $48 \mathrm{hr}$ in buffer solution at $\mathrm{pH} 7.4$ and the drug release was found $82 \%$. In the first few hours there was very low drug release due to the polymer swelling and after the polymer got eroded there was complete drug release because of a swelling of the polymer causes erosion followed by the diffusion indicated in Figure 10.

As the mode of drug release and the mechanism of release, the in vitro release data were determined using different mathematical kinetic model. The in vitro data were obtained of polymeric nanoparticle formulation,

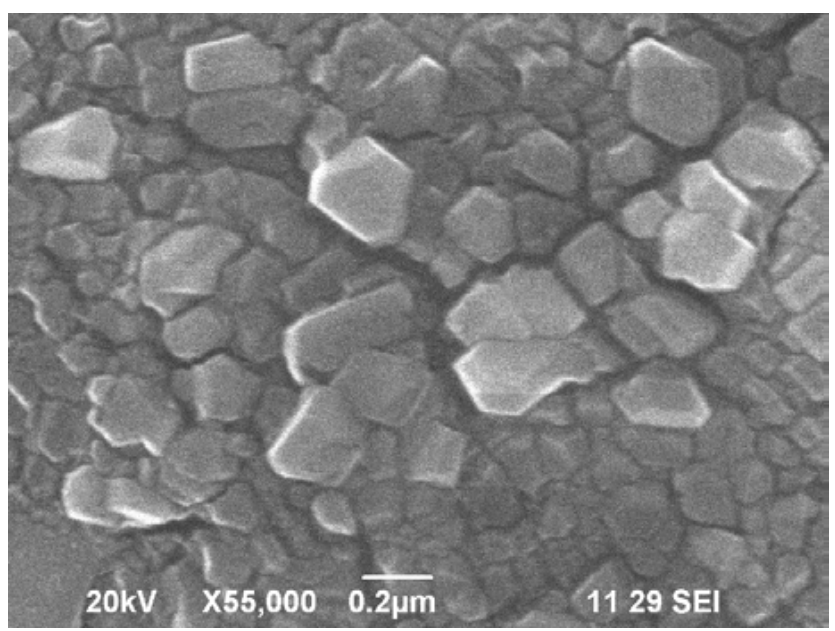

Figure 9: SEM analysis of the Valproic acid loaded polymeric nanoparticle.

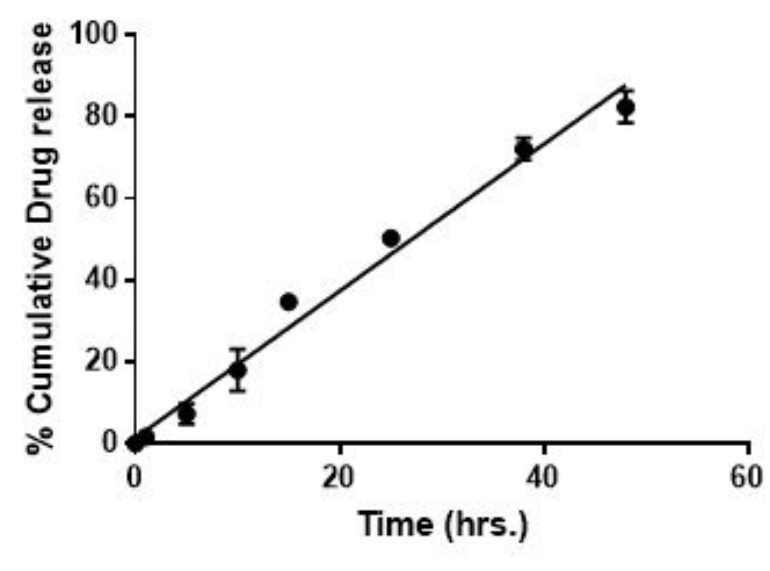

Figure 10: Percentage cumulative drug release at $\mathrm{pH}$ 7.4.

\begin{tabular}{|c|c|c|c|}
\hline \multicolumn{3}{|c|}{ Table 7: Regression value for various kinetic models. } \\
\hline Formulation & Kinetic Models & $\begin{array}{c}\boldsymbol{R}^{2} \\
\text { values }\end{array}$ & Slope (n) \\
\hline $\begin{array}{c}\text { Valproic } \\
\text { acid loaded } \\
\text { polymeric } \\
\text { nanoparticle }\end{array}$ & Zero order & 0.9853 & 3.08 \\
\cline { 2 - 4 } & First order & 0.9860 & 0.05 \\
\cline { 2 - 4 } & Higuchi's model & 0.9961 & 1.35 \\
\cline { 2 - 4 } & Korsmeyer- Peppas model & 0.9428 & 0.06 \\
\cline { 2 - 4 } & Hixon Crowel Model & 0.9957 & 0.07 \\
\hline
\end{tabular}

which was put into the various kinetic models. The result was shown in Table 7 . The regression coefficient $R^{2}$ values determined is as given in Table 7 .

The best linearity was obtained in the Peppa's order Plot for Valproic acid loaded Polymeric nanoparticle formulation. It showed the slope $(\mathrm{n})$ value 1.35 and regression value $\left(R^{2}\right)$ value was 0.9961 . It was following the Non - Fickian model. The other model such as zero order, first order, Higuchi model, Peppa's model and Hixon Crowell model also implemented to study release kinetics. Only the peppa's model regression value $\left(R^{2}\right.$ $=0.9961)$ fitted for the drug release. As per the plots having $R^{2}$ values for zero models 0.9853 , first order 0.9860 , higuchi's model 0.9428 , peppa's model regression value 0.9961 and Hixson Crowell model regression value 0.9957 respectively. Among them, Peppa's model is having the best linearity model with the highest regression value and selected as the kinetic model. Peppa's model is showing that this model is best fit for the polymeric matrix system.

\section{Stability Study}

The stability study was done to give proof that the product stays stable for the given timeframe. The PS, PDI and ZP were estimated in Table 8 to guarantee that the product attributes and drug content of the item stay 
Table 8: Stability study data for optimized formulation.

\begin{tabular}{|c|c|c|c|}
\hline Storage Condition & $\begin{array}{c}\text { Particle } \\
\text { size } \\
(\mathbf{n m})\end{array}$ & $\begin{array}{c}\text { Zeta } \\
\text { Potential } \\
(\mathbf{m V})\end{array}$ & $\begin{array}{c}\text { Polydispersity } \\
\text { Index }\end{array}$ \\
\hline $\begin{array}{c}\text { At time of } \\
\text { preparation }\end{array}$ & $384 \mathrm{~nm}$ & $-15.6 \mathrm{mV}$ & 0.393 \\
\hline $\begin{array}{c}\text { After the stability } \\
\text { testing of } \\
\text { formulation }\end{array}$ & $380 \mathrm{~nm}$ & $-13.3 \mathrm{mV}$ & 0.391 \\
\hline
\end{tabular}

\begin{tabular}{l}
\multicolumn{3}{c|}{ Table 9: Drug and formulation showing IC $_{50} \mu \mathrm{g} / \mathrm{ml}$} \\
Values. \\
\begin{tabular}{c|c|c|}
\hline SI No. & Sample Description & SHSY5Y $\left(\mathrm{IC}_{50} \mu \mathrm{g} / \mathrm{ml}\right)$ \\
\hline 1. & Drug & 23.63364 \\
\hline 2. & Formulation & 42.96435 \\
\hline
\end{tabular}
\end{tabular}

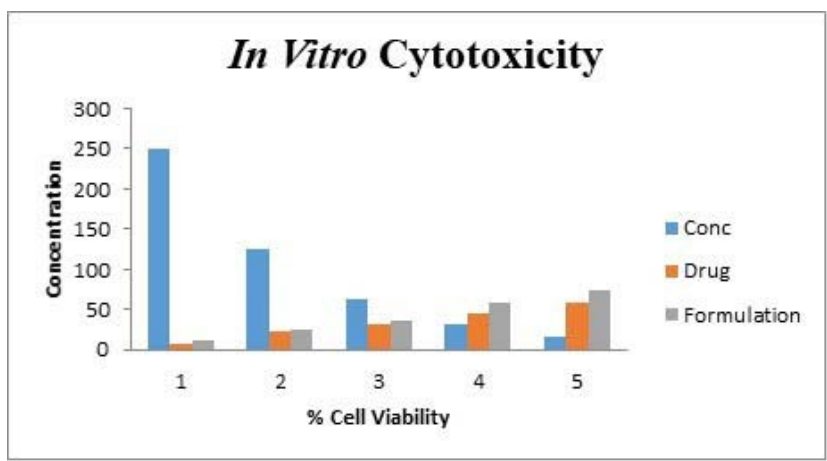

Figure 11: In vitro Cytotoxicity Study of Formulation and Pure Drug.

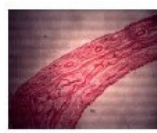

(A)

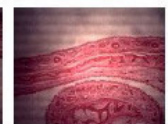

(B)

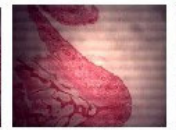

(C)

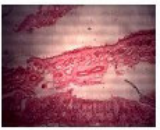

(D)

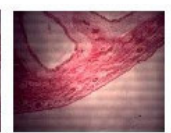

(E)
Figure 12: Nasalcilio toxicity Study: (A) PBS, (B) Placebo, (C) Pure drug, (D) IPA and (E) Formulation.

unchanged. The difference in the PS, PDI and EE was found to be non-significant. The freeze-thaw cycle was done to determine the stability study. After the stability study of the formulation the PS was $380 \mathrm{~nm}$ with ZP $-13.6 \mathrm{mV}$ and PDI 0.391, which is indicating there is no significant changes. So, the formulation was stable after the freeze thaw stability testing. The stability data is shown in the Table 8.

\section{In vitro Cytotoxicity Studies}

Drug and Formulation were screened by MTT assay method on Neuroblastoma cell lines and the result was showed in Table 9 and the graph is shown in Figure 11. Drug and Formulation showed a significant cytotoxicity effect, which $\mathrm{IC}_{50}$ value was found to be drug (23.63364) and formulation (42.96435) respectively. The drug and formulation significantly down regulate SHSY5Y cell viability in a dose-dependent manner, which showed Anti-Alzheimer activity through nasal route without any harm to normal cells.

\section{Histopathological Study Nasal Ciliotoxicity study}

Nasal Ciliotoxicity study has been performed to observe the inflammation and loss of ciliary lines. Each piece of the nasal mucosa was treated with VPA, Placebo, PBS solution, Isopropyl Alcohol and with the VPA loaded polymeric nanoparticle. In placebo no significant effect on ciliary cells, similarly phosphate buffer at $6.4 \mathrm{pH}$ used as negative control also not showing any significant effect on the nasal ciliary part. Isopropyl alcohol as a positive control was showing the high loss in some ciliary lines and inflammation cell are present. In case of pure drug valproic acid was showing loss of some ciliary lines and less inflammation are also present here. Subsequently, if we compared the drug-loaded formulation, which not showing that much inflammation cells and no ciliary damages. So lastly, it was concluded that formulation not showing any toxicity on the nasal mucosa. Histopathological observations of all the 5 samples are shown in Figure 12.

\section{DISCUSSION}

The primary objectives of the project are to repositioning the valproic acid incorporated in the O-CMC nanoparticles through the nasal route for the management of the Alzheimer Disease. The compatibility of drugs and polymer was established using FT-IR and DSC studies. Based on primary research, further optimization of $\mathrm{PNs}$ was carried out using BBD. The PNs were optimization was carried out using Box-Behnken design. The developed Nano-formulations were characterized for various physicochemical parameters, in vitro release and ex vivo nasal toxicity study. Formulated PNs were turbid with the particle size of $363 \mathrm{~nm}$ which is desirable for the nasal to brain targeting along with the entrapment of $70 \%$ of the dose. All the formulations were subjected to toxicological analysis using in vitro cell line assay and nasal histopathological studies. The results demonstrated that PNs were non-toxic and safe for nasal administration. The stability studies of PNs revealed that formulations were highly stable both under refrigeration $\left(4^{\circ} \mathrm{C}\right)$ and room temperature $\left(25^{\circ} \mathrm{C}\right)$ with no significant changes. In the future directions the successful application of 
these attributes requires careful design of characteristics of both the drug formulation and delivery device.

\section{CONCLUSION}

The current research is the primary step for the repositioning of valproic acid for the management of AD. The primary data of the DOE clearly helpful for the reduction of the production cost of the wet laboratory cost and optimized the formulation for more specific drug delivery approach. The research paper specifically focused for the $\mathrm{AD}$ management in the effective manner using the repositioned drug is showed a positive result.

\section{ACKNOWLEDGEMENT}

Authors wish to thank JSS College of Pharmacy, Ooty for providing necessary facilities for carrying the research work.

\section{CONFLICT OF INTEREST}

The authors declare no conflicts of interest.

\section{ABBREVIATIONS}

MCC: Mucociliary clearance; AD: Alzheimer disease; CNS: Central nervous system; TJs: Tight Junctions; A $\beta$ : Amyloid Beta; APP: Amyloid precursor protein; APH1: Anterior Pharynx-defective 1; Nct: Nicastrin; PS: Presenilin; PEN-2: Presenilin enhancer 2; DNA: Deoxy ribose nucleic acid; NFTs: Neurofibrillary tangles; PHF: Paired helical filaments; SF: Straight filaments; NMDA: N-methyl-d-aspartate receptor; CIs: Cholinesterase Inhibitors; GSK3: Glycogen synthase kinase; PPAR $\boldsymbol{\gamma}$ : Peroxisome Proliferator activated receptor $\gamma$; RXR: Retinoid X receptor; apoE: Apo lipoprotein E; BCNU: Bis-chloroethylnitrosourea; VPA: Valproic acid; GABA: Gamma-amino butyric acid;HDAC: Histone acetylation; BBB: Blood brain barrier; CSF: Cerebrospinal Fluid; DOE: Design of Experiments; BBD: Box-Behnken design; PIA: Propylisopropylacetic acid; AEDs: AntiEpileptic drugs.

\section{REFERENCES}

1. Hardy JA, Higgins GA. Alzheimer's disease: The amyloid cascade hypothesis. Science. 1992.

2. Park-Wyllie LY, Mamdani MM, Li P, Gill SS, Laupacis AJD. Cholinesterase inhibitors and hospitalization for bradycardia: A population-based study. PLoS Med. 29(9):e1000157.

3. Ashburn TT, Thor KB. Drug repositioning: Identifying and developing new uses for existing drugs. Nat Rev Drug Discov. 2004;3(8):673.

4. Boolell M, Gepi-Attee S, Gingell JAM. Sildenafil, a novel effective oral therapy for male erectile dysfunction. Br J Urol. 1996;75(2):257-61.

5. Ly PT, Wu Y, Zou H, Wang R, Zhou W, Kinoshita A, et al. Inhibition of GSK3ßmediated BACE1 expression reduces Alzheimer-associated phenotypes. J Clin Invest. 2012;123(1).

6. Neha B, Ganesh BPK. Drug delivery to the brain using polymeric nanoparticles: A review. Int J Pharm Life Sci. 2013;2(3):107-32.

7. Lochhead JJ, Wolak DJ, Pizzo METR. Rapid transport within cerebral perivascular spaces underlies widespread tracer distribution in the brain after intranasal administration. J Cereb Blood Flow Metab. 2015;35(3):371-81.

8. Yang CR, Zhao XL, Hu HY, Li KX, Sun X, Li LCD. Preparation, optimization and characteristic of huperzine a loaded nanostructured lipid carriers. Chem Pharm Bull. 2010;58(5):656-61.

9. Thanki K, Kulthe S, Mandge YRM. Formulation development and IVIVC of controlled porosity osmotic pump tablets of carvedilol phosphate. J Pharm Res. 2011;4(12):4736-40.

10. Sailaja AK, Begum N. Formulation and evaluation of cox-2 inhibitor (etoricoxib) loaded ethyl cellulose nanoparticles for topical drug delivery. Nano Biomed Eng. 2018;10(1):1-9.

11. Abul KM, Khan AA, Khan S, Almalik A, Alshamsan A. Optimizing indomethacin-loaded chitosan nanoparticle size, encapsulation and release using Box-Behnken experimental design. Int J Biol Macromol. 2016;87:329-40.

12. Abousamra MM, Mohsen AM. Solid lipid nanoparticles and nanostructured lipid carriers of tolnaftate: Design, optimization and in-vitro evaluation. Int J Pharm Pharm Sci. 2016;10:100.

13. Alexander A, Khichariya A, Gupta S, Patel RJ, Giri TK, et al. Recent expansions in an emergent novel drug delivery technology: Emulgel. Journal of Controlled Release. 2013;171(2):122-32.

14. Lindskog M, Gleissman H, Ponthan F, Castro J, Kogner PJJ. Neuroblastoma cell death in response to docosahexaenoic acid: Sensitization to chemotherapy and arsenic-induced oxidative stress. Int J Cancer. 2006;118(10):2584-93.

15. Das MS, Mandal S, Patel J. Intranasal mucoadhesivemicroemulsion for neuroprotective effect of curcuminin mptp induced Parkinson model. Brazilian J Pharm Sci. 2017;53(2).

16. De A, Kuppuswamy G, Jaiswal A. Implementation of two different experimental designs for screening and optimization of process parameters for metforminloaded carboxymethyl chitosan formulation. Drug Development and Industrial Pharmacy. 2019;45(11):1821-34. 


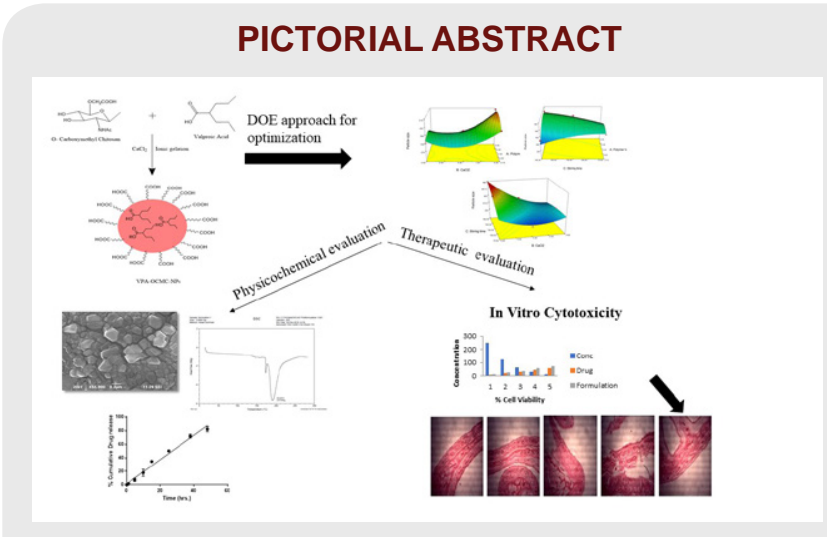

About Authors

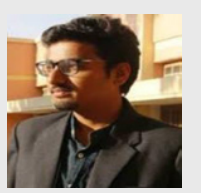

Ayush Jaiswal: $\mathrm{He}$ is presently working as Regulatory Affairs Officer at Mepro Pharmaceuticals. He has done M pharma (Pharmaceutics) from Department of Pharmaceutics, JSS College of Pharmacy, JSS Academy of Higher Education \& Research, Ooty, Nilgiris, Tamil Nadu, India. Having more than 1 year of experience in regulatory field.

\section{SUMMARY}

These preliminary investigations and the through literature survey helped to select excipients facilitated the nasal drug delivery for the treatment of the AD. Further, the compatibility of drugs and polymer was established using FT-IR and DSC studies. The stability studies of the drugs were performed in a mimic condition of the brain $\mathrm{pH}$ to ascertain that drugs stability. Based on primary research, further optimization of PNs was carried out using BBD. Preliminary studies were done for the optimization of the formulation/process variables affecting particle size, entrapment and PDI of the PNs formulation. The optimized batch was formulated using the crosslinking gelation techniques which are one of the most economical and easy manufacturing processes for the formulation. The developed nano-formulations were characterized for various physicochemical parameters, in vitro release and ex vivo nasal toxicity study. The PNs formulations showed control release compared to drug solutions. This was attributed to the barrier properties of the polymer matrix. It can be concluded from these results that PNs are more preferable than the pure drug for the brain targeting due to their size and the nature of the targeting.

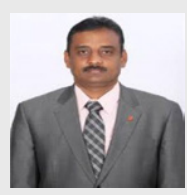

Senthil Venkatachalam: He completed M. Pharmacy in pharmaceutics in the year of 1996, and was awarded with his Ph.D in the year 2011. He is well versed in field of Design and fabrication of Polymeric and lipid based Nano carrier. His thrust research work of 10 years is in development of novel drug delivery systems for effective drug penetration on Blood Brain Barrier and enhance the drug bio availability. He published several research and review papers in both national and international level. He has presented his work in several oral and poster presentations in national and international levels. In his credit of publication "Formulation of Nanostructured Lipids carrier for Acyclovir and enhancement of its Bioavailability" International journal of Chem Tech Research (IF 0.56) and Novel Anionic Polymer as a Carrier for CNS Delivery of Anti-Alzheimer Drug, Drug delivery (IF 4.8) are have high citation value.

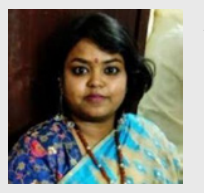

Anindita De: Assistant Professor, College of Pharmacy, JSS Academy of Technical Education Noida. Area of interest cancer drug delivery and drug repositioning. Published 20 research paper in high impact factor journal. Awarded international best poster award and attended 5 international and 10 national conference

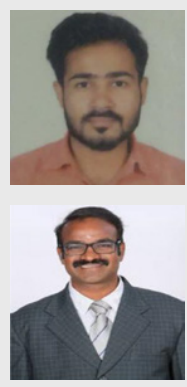

Bhavesh Namdev: $\mathrm{He}$ is presently working as Regulatory affairs Junior officer at Mepro pharmaceuticals. He has done M pharma (Pharmaceutics) from Department of Pharmaceutics, JSS College of Pharmacy, JSS Academy of Higher Education \& Research, Ooty, Nilgiris, Tamil Nadu, India.

Jawahar Natarajan: Earned B.Pharm in AK College of Pharmacy (1999), M. Pharm in KM College of Pharmacy (2002) and Ph.D from JSS University, Mysore. His experience includes both teaching and research, is 18 years. He received several awards, including Career Award For Young Teachers (AICTE, India,) Tony. B Academic Travel Award (SLAS, USA), Best Industrial Pharmacy Poster Award, (FIP, Lisbon, Portugal). He received the travel grants from various funding agencies such as DST, CSIR, and ICMR \& FIP for attending various conferences. Added to his credit he has published 62 articles \& presented 40 research papers. He also authored two books and four book chapters. Filed two Indian patents (Application No.2194/CHE/201, 5144/CHE/2012). He involved as a resource person in national level/ internatonal forums. Guided 50 PG students/ guiding 5 Ph.D scholars. Current area of research is formulation and invitro/invivo evaluation of nanodrug delivery systems for drug delivery and targeting.

Cite this article: Jaiswal A, Venkatachalam S, De A, et al. Preparation, Characterization and Optimization of Repurposed Valproic Acid Loaded Carboxymethyl Chitosan Nanoparticles by Box-Behnken Design for Alzheimer Management. Indian J of Pharmaceutical Education and Research. 2021;55(1s):s75-s86. 